\title{
Behaviour of Ni-based Alloys for Fossil-fired Power Plant Components in the Long-term Creep Regime
}

\author{
Magdalena Speicher ${ }^{a}$, Andreas Klenk ${ }^{b}$, Karl Maile $^{c}$, Eberhard Roos ${ }^{d}$ \\ Materialprüfungsanstalt Universität Stuttgart, Pfaffenwaldring 32, 70569 Stuttgart, Germany \\ a magdalena.speicher@mpa.uni-stuttgart.de, ${ }^{\mathrm{b}}$ andreas.klenk@mpa.uni-stuttgart.de \\ ckarl.maile@mpa.uni-stuttgart.de, ${ }^{\mathrm{d}}$ eberhard.roos@mpa.uni-stuttgart.de
}

Key words: microstructure, creep, thermal aging, Alloy 617, Alloy 263, long-term behaviour

\begin{abstract}
High efficiency steam power plants are planned to operate at temperatures higher than $700^{\circ} \mathrm{C}$ and at a pressure of up to 350 bar. Due to this increase of the steam parameters, Ni-based alloys are required for constructing these plants. Materials testing-based on appropriate manufacturing and design criteria - is necessary in order to have a reliable data base of the relevant design characteristics. Additionally, a better understanding of the specific material behaviour under service like loading conditions for the evaluation of possible damage mechanisms is essential. This paper describes research on the behaviour of thick-walled power plant components made of Alloy 617 mod. and Alloy 263. Results from basic qualification programs with standard specimens including welded joints show the applicability of the materials. Results from creep rupture tests of base material and welded joints and microstructural investigations to obtain information on precipitations and dislocations in the virgin and aged conditions are presented. Information on the influence of chemical composition on creep rupture was obtained by analysing creep rupture data sets.
\end{abstract}

\section{Introduction}

Even in the future, coal will play a significant role in ensuring our energy production. In steam power plants, resource-saving modes of operation become possible by use of new technologies providing a significant increase of efficiency and thereby a considerable reduction of pollution. This technology is suitable to substitute old power plants and can thereby contribute to reaching the goals outlined in the agreements for climate protection. These new technologies rely on an increase of the steam parameters pressure and temperature. Materials used up to now are not appropriate and the use of Ni-based alloys has to be intensified. Especially the increase in temperature sets considerable demands on long-term stability, corrosion/oxidation resistance, strength and deformation potential of the structural materials to be used. Moreover the local microstructure of the material in the component e.g. in welded joints or cold formed tubes has to be considered.

Currently running programmes for material optimisation for $700^{\circ} \mathrm{C}$ power plants place emphasis on the provision of technology for future high performance power plants. These programmes are based on knowledge gained from research projects for material qualification for the $650^{\circ} \mathrm{C}$ application range, which is an essential prerequisite for the $720^{\circ} \mathrm{C}$ power plant. The focus, however, has been shifted to the application of Ni-based materials. Projects like MARCKO700 and COORETEC DE4 [1, 2] qualify different martensitic materials and Ni-based alloys (base materials and welded joints) for both, the application in steam turbines and boiler plants. Experiments (creep tests, component tests) form the basis for a safe prediction of the long-term behaviour of the tested materials under operating conditions and hence for their accreditation as construction materials in pressure vessel design. Hereby, the focus is placed on aspects like deformation and failure behaviour, damage mechanisms, microstructural evolution and damage accumulation. The important substantial aspects of such investigations include the verification of long-term creep strength of materials and especially weldments, the optimisation of manufacturing and the further demonstration of the fabricability. 


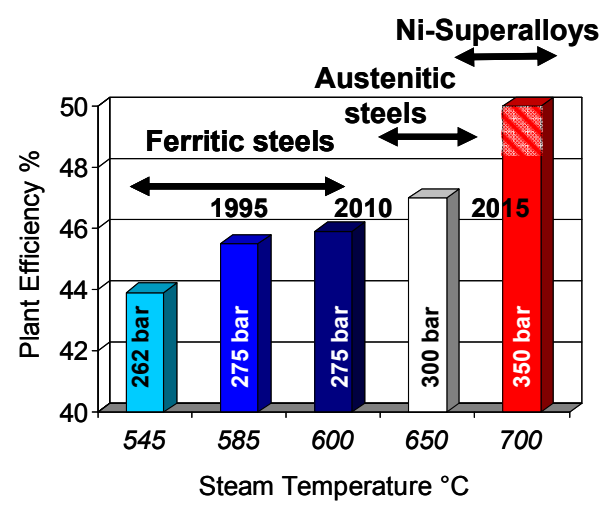

Fig. 1: Trends in power plant technology in the near future

\section{Creep behaviour and microstructural evolution of Alloy 617 mod. and Alloy 263}

For Alloy 617 mod., a reasonably good long-term data base for base material and welded joints of tubes and pipes obtained by crossweld tests already exists [1, 3, 4]. The results obtained with crossweld specimens from SMAW- and TIG-girth welds of tubes and pipes for temperatures of $700^{\circ} \mathrm{C}$ and $750^{\circ} \mathrm{C}$ are within the base material scatter band. Long-term tests in excess of $10,000 \mathrm{~h}$ testing time show a tendency towards the base material mean values, Fig. 2.

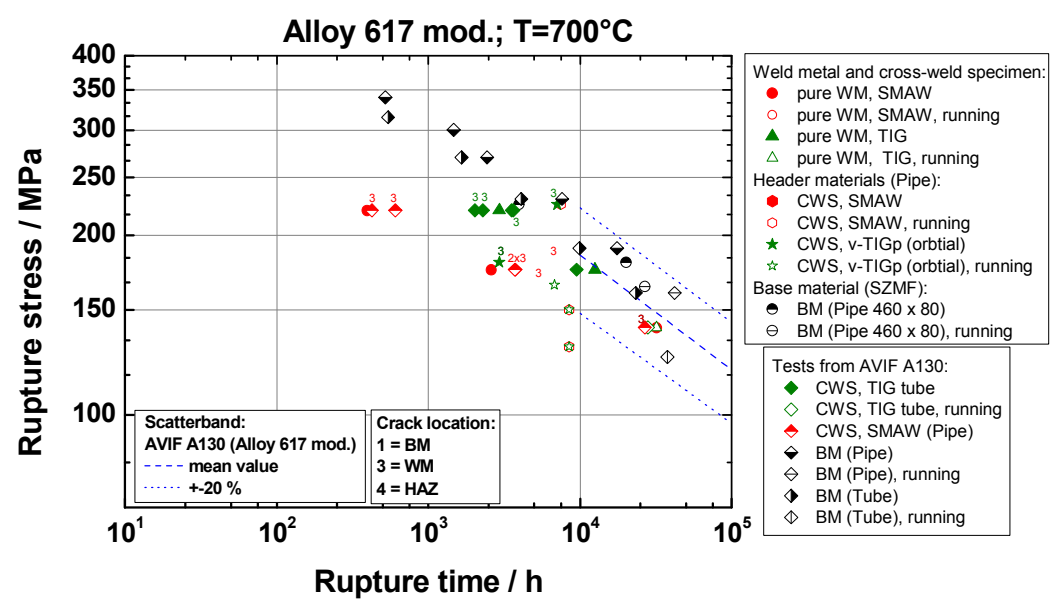

Fig.2: Results on crossweld specimens (CWS) for different similar welds of Alloy 617 mod. [1]

The features of the precipitate microstructure which develop during the manufacturing process and their changes during thermal and thermo-mechanical loading are essential for the long-term performance of the materials. Precipitates were identified and characterized and the dislocation density was determined for different states of the materials with the help of OM, SEM and TEM. The chemical composition of phases was determined using TEM replica and the size of precipitates using thin metal foils for TEM examination. The gamma prime phase was identified by diffraction. Damage evolution was studied focussing on the formation of cavities and micro-cracks. The chemical composition of Alloy 617 and Alloy 263 is shown in Table 1. Alloy 617 consists of nickel, chromium, cobalt, molybdenum, aluminium and titanium. The material is solid-solution strengthened and carbide strengthened. Alloy 263 consists of nickel, the same content of chromium and cobalt, molybdenum, titanium, aluminium and niobium. Its properties depend on the effect of precipitation hardening mainly of $\gamma^{\prime}$ phase. In polycrystalline Ni-based alloys used in the boiler and turbine engineering the following precipitates can be observed: carbides: MX (mainly TiC) and $\mathrm{M}_{23} \mathrm{C}_{6}, \mathrm{M}_{6} \mathrm{C}, \mathrm{M}_{7} \mathrm{C}_{3}$ and $\gamma^{\prime}$ phase: type $\mathrm{Ni}_{3}(\mathrm{Al}, \mathrm{Ti})$ or $\mathrm{Ni}_{3} \mathrm{Nb}$, there will be a transformation into $\gamma^{\prime \prime}, \delta$ phase $(\mathrm{Nb})$ or $\eta$ phase.

The microstructure of Alloy 617 mod. consists of an austenitic matrix with carbides. This material has many twins and grain size is inhomogeneous. Typical precipitates are carbides $\mathrm{M}_{23} \mathrm{C}_{6}$ $(\mathrm{Cr}, \mathrm{Mo})_{23} \mathrm{C}_{6}, \mathrm{M}_{6} \mathrm{C}(\mathrm{Mo}, \mathrm{Cr}, \mathrm{Fe})_{6} \mathrm{C}, \mathrm{Ti}(\mathrm{C}, \mathrm{N})$ in the initial state and $\gamma^{\prime}$ and also $\delta$ phase after high temperature service. Other possible precipitates in Alloy 617 are described in [5]. 


\begin{tabular}{|c|c|c|c|c|c|c|c|c|c|c|c|c|}
\hline Material & & $\begin{array}{l}\mathbf{C} \\
\% \\
\end{array}$ & $\begin{array}{l}\text { Al } \\
\% \\
\end{array}$ & $\begin{array}{c}\text { Co } \\
\% \\
\end{array}$ & $\begin{array}{l}\mathrm{Cr} \\
\% \\
\end{array}$ & $\begin{array}{c}\text { Mo } \\
\%\end{array}$ & $\begin{array}{c}\mathrm{Nb} \\
\%\end{array}$ & $\begin{array}{l}\mathrm{Ti} \\
\% \\
\end{array}$ & $\begin{array}{l}\text { B } \\
\% \\
\end{array}$ & $\begin{array}{c}\mathrm{Fe} \\
\% \\
\end{array}$ & $\begin{array}{l}\mathrm{Ni} \\
\% \\
\end{array}$ & \\
\hline \multirow{4}{*}{$\begin{array}{c}\text { Alloy } \\
617\end{array}$} & $\min$. & 0,05 & 0,80 & 11,0 & 21,0 & 8,0 & & 0,30 & 0,002 & & & E.A. \\
\hline & $\max$ & 0,08 & 1,30 & 13,0 & 23,0 & 10,0 & & 0,50 & 0,005 & 1,50 & Bal. & A130 \\
\hline & $\min$. & 0,05 & 0,60 & 10,0 & 20,0 & 8,0 & & 0,20 & & - & & VdTÜV \\
\hline & $\max$ & 0,10 & 1,50 & 13,0 & 23,0 & 10,0 & & 0,50 & & 2,0 & Bal. & 485 \\
\hline \multirow{2}{*}{$\begin{array}{c}\text { Alloy } \\
263\end{array}$} & $\min$. & 0,04 & 0,3 & 19,0 & 19,0 & 5,6 & & 1,90 & & & & \\
\hline & $\max$ & 0,08 & 0,6 & 21,0 & 21,0 & 6,1 & 2,2 & 2,40 & 0,005 & 0,7 & Bal. & ThyssenKru \\
\hline
\end{tabular}

Table 1: Chemical composition of Alloy 617 and Alloy 263

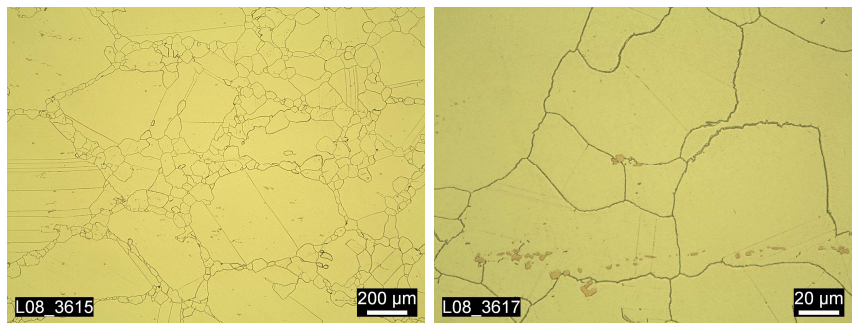

Fig.3: Austenitic structure of initial state of Alloy 617 mod. (thick-walled pipe)

Some of the coarse particles in Fig. 3 are titanium carbides and carbonitrides. TEM images from the initial state are shown in Fig. 4. The Ni-based materials have microstructures which differ when comparing a matrix region to a grain boundary. The microstructural features are therefore distinguished according to these locations. At grain boundaries (GB) and within the grain $\mathrm{M}_{23} \mathrm{C}_{6}$ carbides were identified.
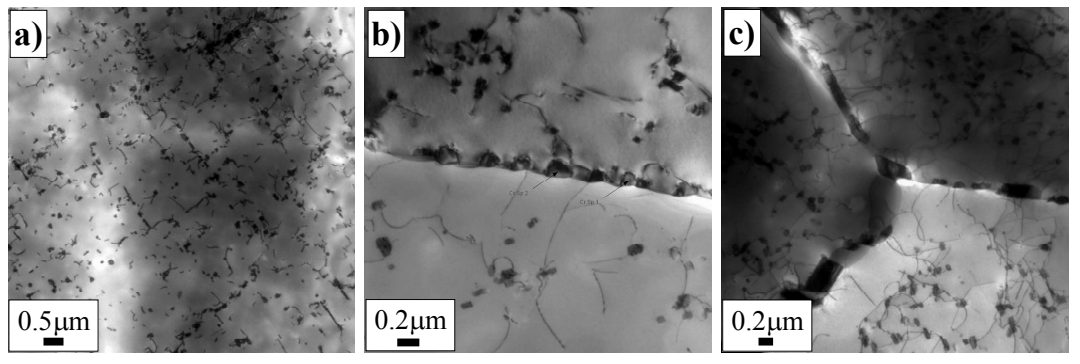

Fig.4: TEM bright-field images of initial state of Alloy 617 mod.; a) within the grain b, c) grain boundary with dislocations
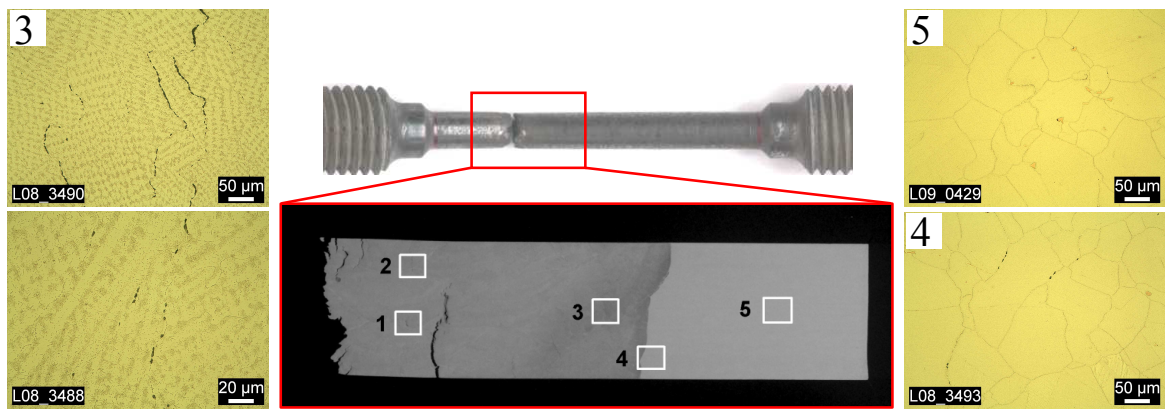

Fig.5: Uni-axial creep rupture specimen (crossweld) after creep loading, Alloy 617 mod.

In Fig. 5 the macrograph of a crossweld specimen from a welded thick-walled pipe ruptured after long-term creep $\left(26,700 \mathrm{~h}\right.$ at $\left.700^{\circ} \mathrm{C} / 140 \mathrm{MPa}\right)$ together with micrographs from different locations are shown. Different zones of the sample are considered: base material (BM), heat affected zone (HAZ) and weld metal (WM). The crack appeared in the weld metal and formation of creep cavities at grain boundaries could be observed in the HAZ, close to the fusion line, perpendicular to the direction of loading. In the weld metal, interdendritic cavities are visible but also cavity chains and micro-cracks. Grain boundaries are covered with precipitates. The hardness increases from approximately $210 \mathrm{HV} 10$ in the as-received condition to $270 \mathrm{HV} 10$ (BM) and $286 \mathrm{HV} 10$ (HAZ). In the WM the hardness is 345 HV10. 
The TEM investigations were performed within the grain and at grain boundaries, Fig.6. In the grain chromium carbides and also $\gamma^{\prime}$ precipitates could be observed in all the three zones of the specimen. At grain boundaries, Cr-rich carbides $\mathrm{M}_{23} \mathrm{C}_{6}$ and Mo-rich $\mathrm{M}_{6} \mathrm{C}$ were found in the $\mathrm{BM}$, in the head of the specimen $70 \%$ of the first and $30 \%$ of the latter, in the shank $80 \%$ and $20 \%$, respectively. In the weld metal, no $\mathrm{M}_{23} \mathrm{C}_{6}$ was observed. Gamma prime size in the head and shank is similar at approximately $90 \mathrm{~nm}$. In the weld metal, $\gamma^{\prime}$ precipitates are larger $(112 \mathrm{~nm})$. The shape of $\gamma^{\prime}$ is mostly spheroid. In the WM, Mo-rich needle-like precipitates were found, representing sigma, or laves phase. However, these phases could not be clearly identified by diffraction. The dislocation density is highest in the weld metal with $11.8 \pm 3.8 \cdot 10^{9} \mathrm{~cm}^{-2}$.
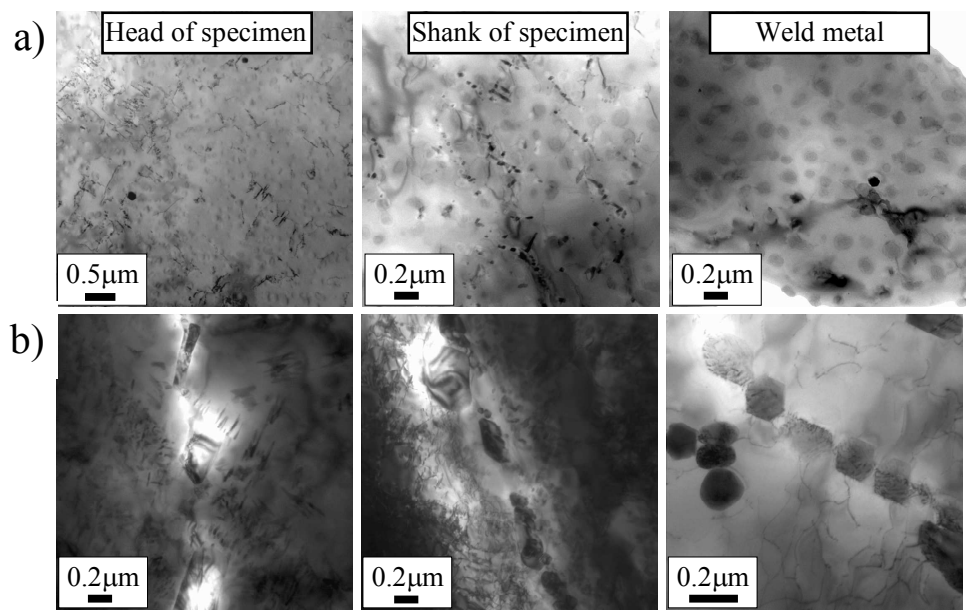

Fig.6: TEM bright-field images of Alloy 617 mod. $\left(\mathrm{T}=700^{\circ} \mathrm{C}, 140 \mathrm{MPa}, 26,700 \mathrm{~h}\right)$, a) within the grain, b) at grain boundary

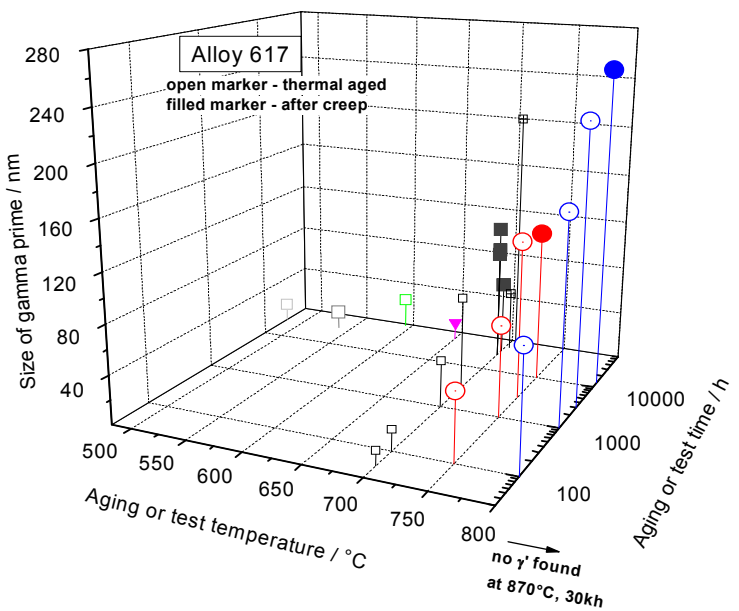

Fig.7: Size of gamma prime precipitates as function of temperature and time, Alloy 617

The results of TEM investigations were compared with previous data $[6,7,8]$. The size of $\gamma^{\prime}$ as a function of temperature and time shows no significant difference after thermal aging and creep loading, Fig. 7. At lower temperatures $\gamma^{\prime}$ was only found after longer times at a size of $15 \mathrm{~nm}$, at higher temperatures particles of $96 \mathrm{~nm}$ size formed after shorter times. At $700^{\circ} \mathrm{C}$, the coarsening of gamma prime is observed and under thermal stress also at $750^{\circ} \mathrm{C}$ and $800^{\circ} \mathrm{C}$. The coarsening is fastest at $800^{\circ} \mathrm{C}$. At $870^{\circ} \mathrm{C}$ after $30,000 \mathrm{~h}$ no gamma prime was found. The coarsening of $\gamma^{\prime}$ phase could be described by the LSW-law according to [6] using the activation energies for diffusion of aluminium and titanium in nickel.

The influence of chemical composition on creep rupture behaviour was studied considering boron, titanium and aluminium. The results at $700^{\circ} \mathrm{C}$ for boron and aluminium are shown in Fig. 8 . Melts with a moderate content of boron and with higher contents of titanium tend to have better creep resistance. For aluminium, no clear trend could be observed. However, at this point it must be noted that the significance of considering only one single element is limited. 

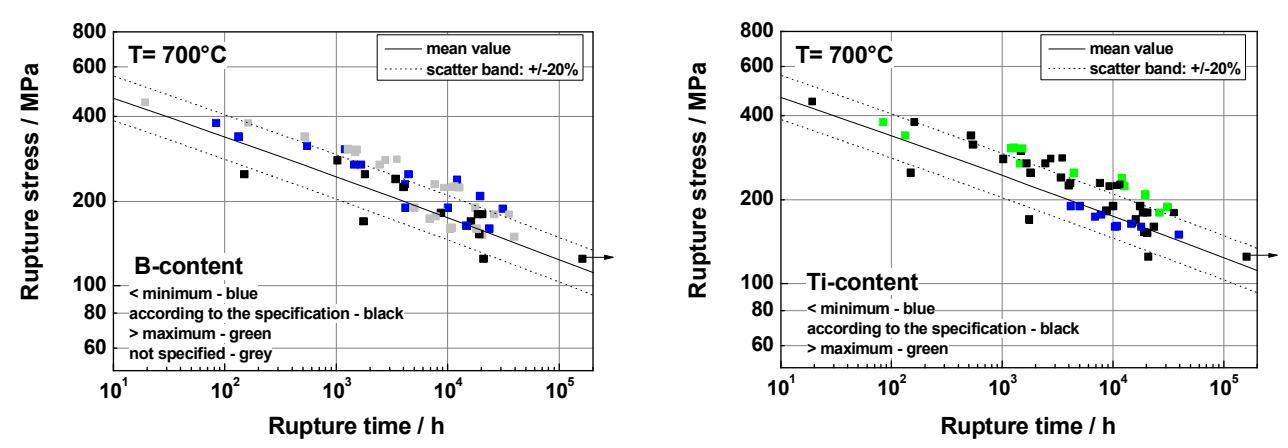

Fig. 8: Alloy 617: influence of chemical composition on creep rupture

\section{Microstructural evolution Alloy 263}

The investigations of the Ni-based alloy 263 were carried out on a thick-walled pipe. Hardness measurements showed $171 \mathrm{HV} 10$ after solution annealing, $262 \mathrm{HV} 10$ after $4 \mathrm{~h}$ and $265 \mathrm{HV} 10$ after $8 \mathrm{~h}$ precipitation hardening at $800^{\circ} \mathrm{C}$. For a typical hardening temperature, the hardness increase after $8 \mathrm{~h}$ ageing time is small compared to $4 \mathrm{~h}$. Size and number of particles of precipitates of both states are almost the same. Typical precipitates are: $\mathrm{M}_{23} \mathrm{C}_{6}, \mathrm{MC}$ and $\gamma^{\prime}$ in the initial state. After thermal exposure, $\eta$ phase $(\mathrm{Ni}, \mathrm{Co})_{3} \mathrm{Ti}$ may appear. Further precipitates in Alloy 263 are described in [9]. In Fig.9 the microstructure of the initial state (Fig.9a) and after thermal aging (Fig.9b) is shown. Many twins and coarse $\mathrm{TiC}$ and $\mathrm{Ti}(\mathrm{C}, \mathrm{N})$ particles could be observed in both states. The grain size changed only slightly. After thermal aging, the grain boundaries are covered with precipitates. The hardness increases from $262 \mathrm{HV} 10$ to $339 \mathrm{HV} 10$. $\eta$ phase can already be detected by optical microscopy.

In initial state gamma prime and carbides $\mathrm{M}_{23} \mathrm{C}_{6}$ could be found within the grain, Fig. 10. At grain boundaries, $\mathrm{M}_{23} \mathrm{C}_{6}$ have a spheroidal and needle-like morphology. After thermal aging, $\gamma^{\prime}$ precipitates are larger and the number of particles decreases. Also a $\eta$ needle-like phase, which is surrounded by $\gamma^{\prime}$ could be seen. There is only a small change in chemical composition of gamma prime. After thermal stress exposure it contains a lower amount of chromium but more aluminium.
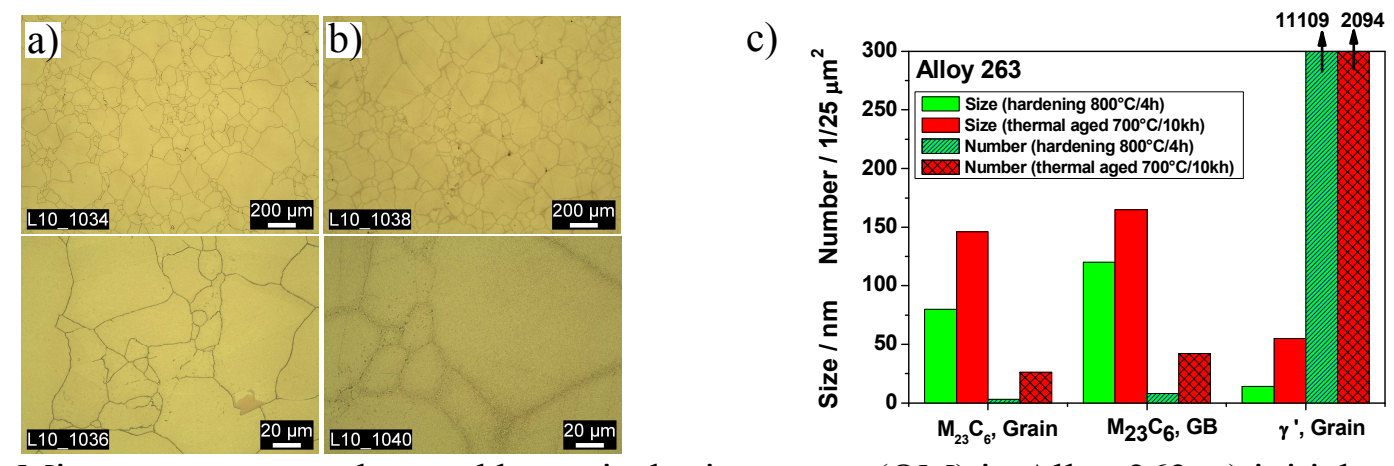

Fig.9: Microstructures as observed by optical microscopy (OM) in Alloy 263, a) initial condition

b) after thermal aging at $700^{\circ} \mathrm{C}$ for $10,000 \mathrm{~h}$; c) Size distributions of precipitates in Alloy 263 in initial state and after thermal aging (TEM analysis)

The quantitative analysis for Alloy 263, Fig. 9c), shows a size of $14 \mathrm{~nm}$ of $\gamma^{\prime}$ phase in the initial state, in which also $\mathrm{M}_{23} \mathrm{C}_{6}$ at $\mathrm{GB}$ and within the grain and some Ti-rich MC (TiC) could be found. A reduced number of $\gamma^{\prime}$ particles at a size of $55 \mathrm{~nm}$ and a coarsening of $\mathrm{M}_{23} \mathrm{C}_{6}$ at $\mathrm{GB}$ and within the grain was observed in thermal aged condition, where besides some Ti-rich $\mathrm{MC}$ (TiC) as in the initial state and also some $\eta$ phase particles were observed. This indicates the beginning of $\eta$ phase formation, as shown in the TTP-diagram in [9]. The results shown here correspond to the results of Hicks [10], but the transformation of $\gamma^{\prime}$ into the $\eta$ phase depends on chemical composition of the alloy. Further studies are necessary to characterise coarsening of the gamma prime phase as a function of time. 


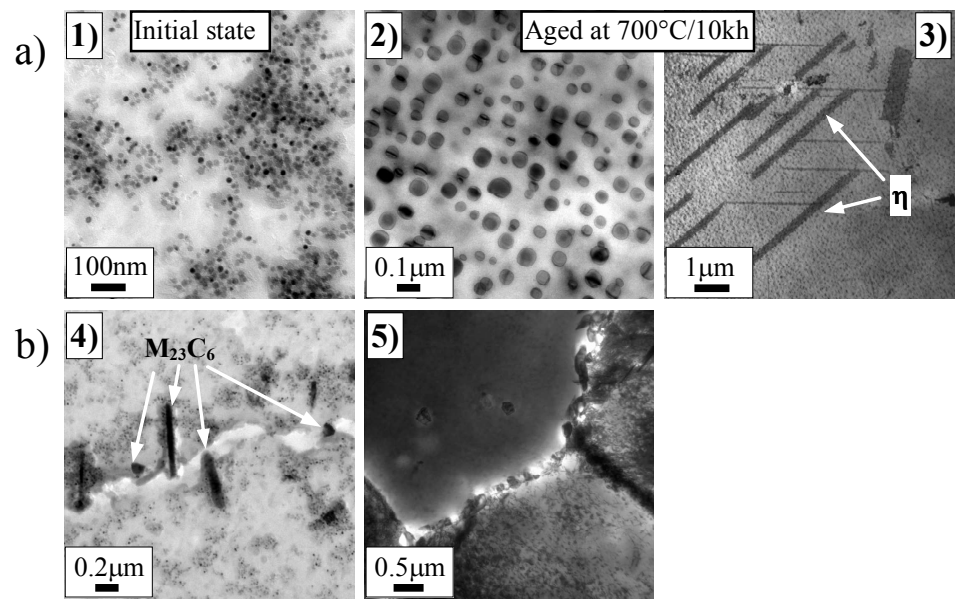

Fig.10: TEM images of Alloy 263, a) within the grain, b) at grain boundary; 1, 2, 4: replicas, 3, 5: thin foils

\section{Summary and Conclusions}

Design, materials and requirements for the materials used in $700^{\circ} \mathrm{C}$ power plant technology were outlined. Qualification programmes are under way and the results obtained in the present study demonstrate that Alloy 617 mod. due to good mechanical properties and oxidation resistance has great potential for operating temperatures above $700^{\circ} \mathrm{C}$. Microstructural analyses were performed in order to understand the evolution of microstructure, which has a decisive influence on the long-term properties. For Alloy 263 which has good creep properties, influence of duration of precipitation hardening and effects of thermal ageing on microstructure was investigated by optical and transmission electron microscopy. For this material further investigations and long-term experiments are necessary to gain a better understanding of microstructural processes and creep behaviour.

\section{References}

[1] Research Project Marcko 700, Final report of MPA Stuttgart, AVIF-A215, (2010).

[2] Current COORETEC-Project DE4, BMWi - Project-Nr. 0327705Y.

[3] A. Klenk et al., in: 28. Vortragsveranstaltung „Langzeitverhalten warmfester Stähle und Hochtemperaturwerkstoffe“, (2005), Düsseldorf, p. 115-126.

[4] G. Cheng et al., in: 5th International Conference on Advances in materials Technology for Fossil Power Plants, Session 3A-07, October 3-5 (2007), Marco Island, USA.

[5] H. Kirchhöfer: Dissertation, RWTH Aachen, Germany, (1983).

[6] Q. Wu: Dissertation, Division of Research and Advanced Studies of the University of Cincinnati, USA, (2006).

[7] M. Cabbibo et al, in: Journal of Materials Science, Vol. 43, (2008) 8, p. 2912-2921.

[8] R. Krischna et al., in: 2nd International ECCC Conference on Creep \& Fracture in High Temperature Components - Design \& Life Assessment (2009), p.1223-1235.

[9] J. Zhao et al, in: Metallurgical and Materials Transactions A, Vol. 32A, (2001), p.1271-1282.

[10]B. Hicks and M. Heap: Report No. B48749, Lucas Gas Turbine Equipment Ltd., Materials Laboratory, Burnley, Sept. 25, (1968). 